\title{
Modelling of Music Learning Process Based on Knowledge Sharing
}

\author{
https://doi.org/10.3991/ijet.v14i23.12257 \\ Yifeng Li \\ Northeast Agricultural University, Harbin, China \\ Liyifeng1929@126.com
}

\begin{abstract}
In the Internet era, knowledge sharing makes learning more efficient and effective. Drawing on knowledge sharing theories, this paper firstly analyses the influencing factors of knowledge sharing in individual or enterprise. The analysis shows that, knowledge sharing is highly self-incentive, for shared knowledge is more active and more likely to be shared again; knowledge sharing on the Internet is affected by Internet technology, the location of the sharer, and the inner and outer incentive mechanisms. On this basis, the music learning process was modelled based on knowledge sharing, learning and innovation, and used to analyse the music learning process considering the correlation between knowledge sharing and knowledge innovation. The research findings lay a solid theoretical basis for music professionals and enthusiasts to improve their learning and skills.
\end{abstract}

Keywords-Knowledge sharing; music learning; music learning process model; knowledge innovation

\section{$1 \quad$ Introduction}

In recent years, with the rapid development of information technology and network technology, the developmental modes in various fields of society have changed, and the teaching methods and learning modes of individuals have also undergone tremendous changes. In the social education environment, the development of new media and new technologies have also promoted the optimization and improvement of public education functions, and gave birth to a new education and learning model of information education and knowledge sharing [1-3]. New cognition, theory, technologies, and products are growing at a faster rate. People can improve learning efficiency through knowledge sharing, without the need of on-the-spot learning by tedious procedures or channels [4-6]. Meanwhile, the knowledge sharing model has shown the network effect of knowledge to a certain extent, reducing the cost of learning new knowledge or skills [7-8]. Therefore, it is the key and hot issue of education development on how to use network technology for more knowledge sharing, and more efficient learning and work nowadays.

Different from other subjects, the music learning depends more on the development of music sense and mastery of music rhythm. The knowledge sharing plays a 
significant role in the learning of musical skills [9-11]. Based on their own experience, and self-innovation and discovery in the learning process, the imparter can further realize the sublimation of knowledge and self-skills through knowledge sharing, and also facilitate the learning of other professional individuals [12-14]. Music learning requires correct learning experience and theoretical guidance, the appropriate learning model and music knowledge sharing for effectively improving the learning efficiency [15-17]. Many researches have been carried out in the field of music learning, but there are still few theoretical guidance or theoretical models of the music learning process [18-20]. In view of this, an in-depth research should be conducted to improve the role of music knowledge sharing, and provide a more convenient way for music learners or amateurs.

For the above problems, this paper firstly proposes an improved knowledge sharing model for music learners by characterizing the knowledge structuralization and analysing the transmission mode of knowledge based on the knowledge sharing theory. Then, Combining the relevant experience and theoretical basis of music learning, it studies the intrinsic relevance between knowledge sharing and knowledge innovation, and proposes the optimized music learning process model. This study provides convenience for the transfer, transmission and learning of music knowledge, and also theoretical support for the improvement of musicians' skills and learning efficiency.

\section{Knowledge Sharing Theory and Model}

\subsection{Concept of knowledge sharing and related theories}

Knowledge sharing is the transformation of implicit knowledge and explicit knowledge in the process of communication. Implicit knowledge refers to behaviour, value, emotion and experience etc. As the result of individuals' long-term accumulation, it's highly personalized, and generally difficult to quantify. Explicit knowledge is objective, systematic and tangible information based on certain rules. Knowledge sharing is an exchange of knowledge. Through effective communication, both sides can understand each other, achieving the goal of knowledge sharing. Knowledge sharing is also a process of increasing value and innovation in the process of transmission. The exchange of ideas and information can ensure increasing each person's knowledge reserves, and further expanding the creative value and innovation effect of knowledge.

An emerging knowledge sharing model in the network environment is the informal learning community. Knowledge sharing is a process of transferring from the community to the individual, and also from individual learning to the community. Informal knowledge sharing involves two aspects: the exchange and transfer of knowledge between scholars and community scholars; the mutual sharing between the community and members.

The sharing system of learning consists of the knowledge sharing object, the knowledge sharing subject, and the knowledge sharing environment. Knowledge sharing is the use of certain means to promote mutual communication, realize 
knowledge transformation and communication, and finally create new knowledge under certain circumstances; in the learning community, the members contribute knowledge to the community, while the community provides knowledge to the members, which forms the basic model of knowledge sharing, as shown in Figure 1.

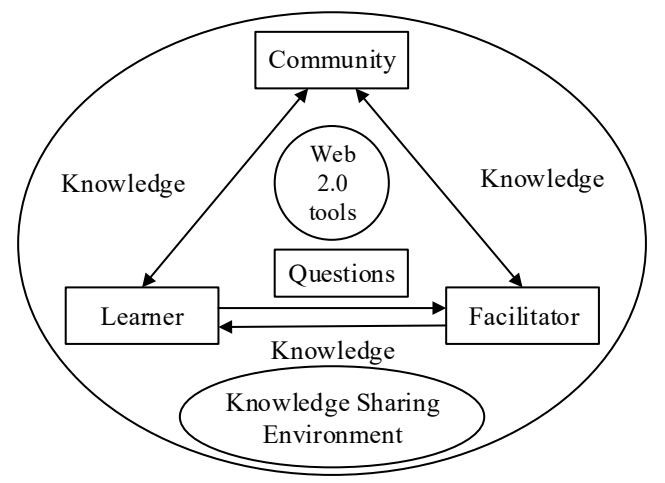

Fig. 1. Model of knowledge sharing

\subsection{Knowledge sharing process}

Knowledge sharing is a two-way dynamic communication process. But some involves one-way flow, e.g., master teaches apprentices, teachers give lectures, and employees learn from the knowledge base. One-way flow can be called a study-type process, while two-way flow is an exchange-oriented process. Figure 2 shows the process of knowledge one-way flow. In this process, the learner of knowledge learns explicit knowledge from the learning library; if they need to learn implicit knowledge, it's necessary to consult with the knowledge manager who then helps to build the connection between the knowledge transferors and learners, and also record and supervise the whole process.

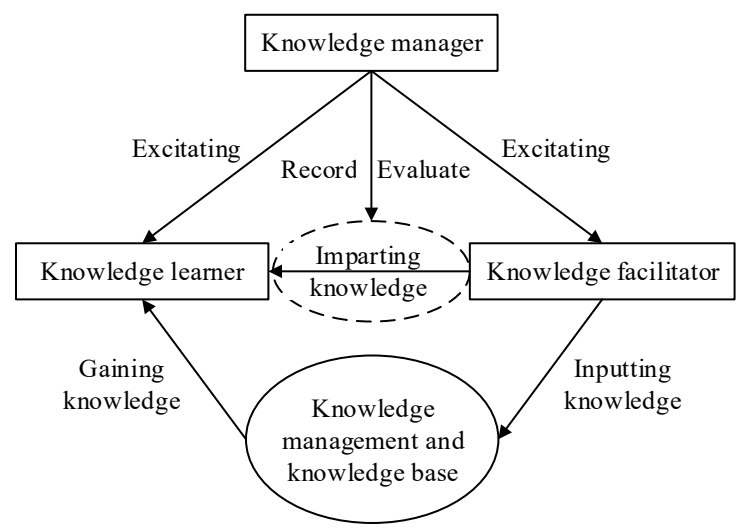

Fig. 2. Learning process of knowledge sharing 
The exchange-oriented process refers to that both parties have the role of learning and imparting at the same time, that is, the superposition of two one-way flows. The subject has a dual role. For a particular study-type process, the subject's role is relatively fixed, but as time goes by and the venue changes, the learner may change to the instructor, and the instructor will become the learner. Knowledge managers will also become transferrers or learners, and the subject will change with the occasion and time. This indicates the subject's dynamic nature of knowledge sharing. The relationship between the roles of subjects is shown in Figure 3.

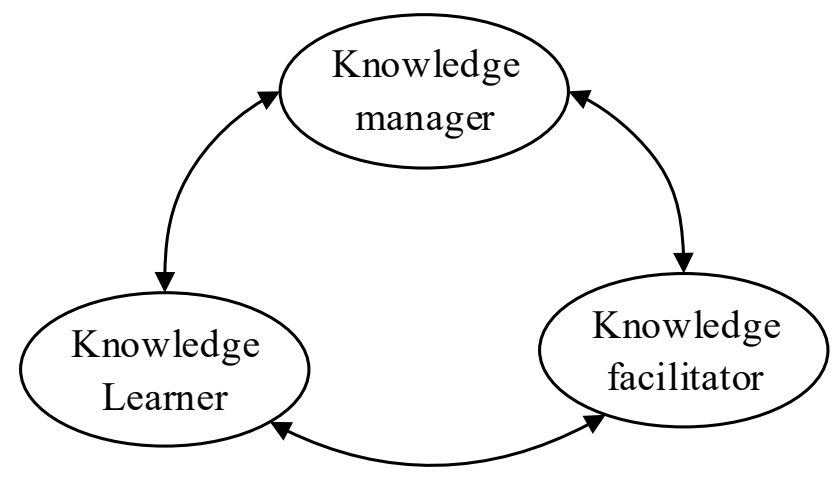

Fig. 3. Transforming the Role of Knowledge Sharing Subject

In the process of sharing, knowledge flows in the state of a certain medium. Knowledge flow is a form of dynamic existence in knowledge sharing, which is a process of transfer and absorption of knowledge between different subjects, containing three attributes: there are starting and ending points, as well as directions; it has the technical means of knowledge sharing, with carriers and media as the main technical means; the influence of knowledge flow is all-round. The model of knowledge flow is shown in Figure 4.

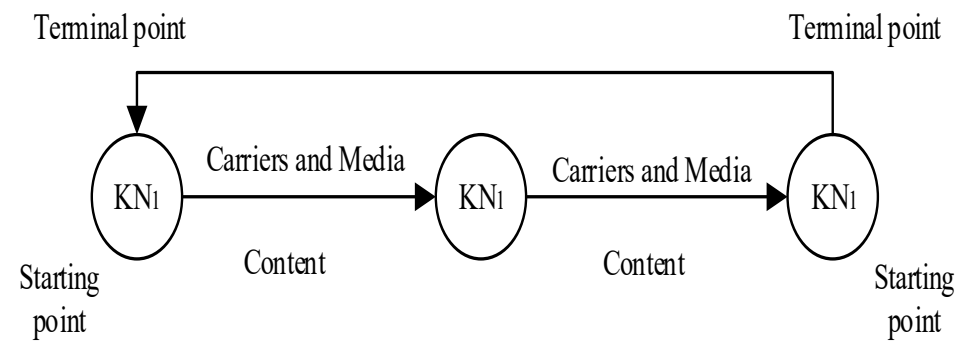

Fig. 4. Knowledge flow

Figure 5 shows that knowledge sharing has highly self-incentive, for shared knowledge is more active and more likely to be shared again, otherwise, it shall be 
less shared. From the perspective of economics, the sharing activities must be formed by taking incentive measures, and spontaneous and voluntary knowledge sharing is difficult to form. It can also be seen from the figure that there is a critical point in knowledge sharing; as the degree of sharing increases, the internal power of sharing also increases gradually, and it is easy to form a virtuous circle. But external incentives are often needed from the beginning to the shared critical point, so as to move from the bottleneck to a virtuous circle.

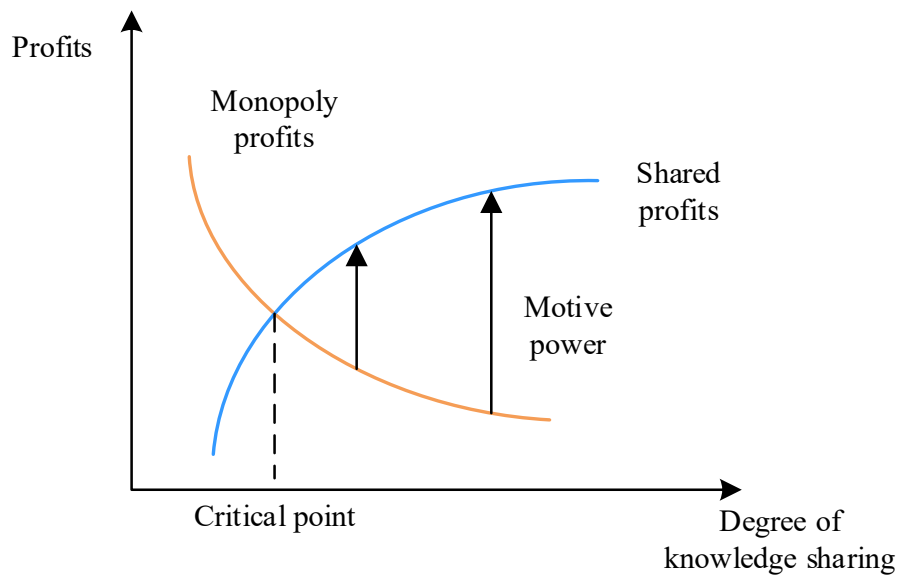

Fig. 5. Motive power of knowledge sharing

In the process of music learning, knowledge imparters and knowledge learners have obstacles in knowledge sharing. From the perspective of knowledge imparters, there is a lack of confidence in the music teaching system, and unclear reward mechanism, so the self-motivation for teaching is insufficient; from the perspective of knowledge learners, they are the absorbers of knowledge, and their own psychological factors, attitudes and learning ability are the main obstacles.

Table 1. Percentage of barriers

\begin{tabular}{|l|c|c|c|c|c|}
\hline \multicolumn{1}{|c|}{ Factor } & $\begin{array}{c}\text { Learning } \\
\text { environment }\end{array}$ & $\begin{array}{c}\text { Level of } \\
\text { teacher }\end{array}$ & $\begin{array}{c}\text { Student's } \\
\text { attitudes }\end{array}$ & $\begin{array}{c}\text { Learning } \\
\text { ability }\end{array}$ & $\begin{array}{c}\text { Psychological } \\
\text { factor }\end{array}$ \\
\hline Percentage & $32 \%$ & $25 \%$ & $17 \%$ & $20 \%$ & $6 \%$ \\
\hline
\end{tabular}




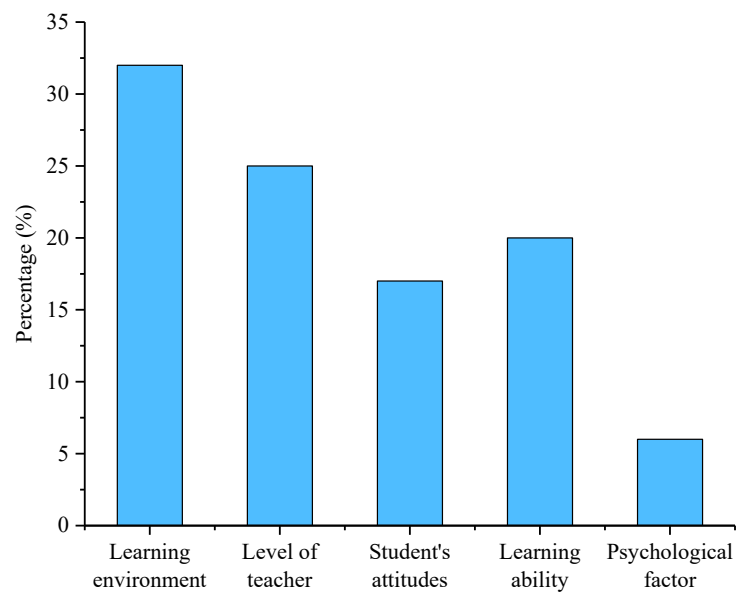

Fig. 6. Obstacles to knowledge sharing in music learning

Table 1 and Figure 6 show the survey results of obstacles to knowledge sharing in music learning. It can be seen that the top three obstacles to knowledge sharing are the learning environment, the teaching level of teachers, and the learning ability of students, accounting for $77 \%$, indicating that these obstacles in music learning knowledge sharing include not only the knowledge imparters themselves, but also the knowledge learners.

Knowledge sharing is phase-based, as shown in Figure 7. In the dynamic process of knowledge sharing, the disseminators of knowledge constantly create new knowledge; the innovative knowledge of individuals is limited, but the knowledge formed by the group achieves a phased breakthrough in the process of continuous accumulation. The staged development of knowledge sharing requires the further improvement of the reward strategy to match the development, which in turn puts higher demands on the reward strategy of knowledge sharing.

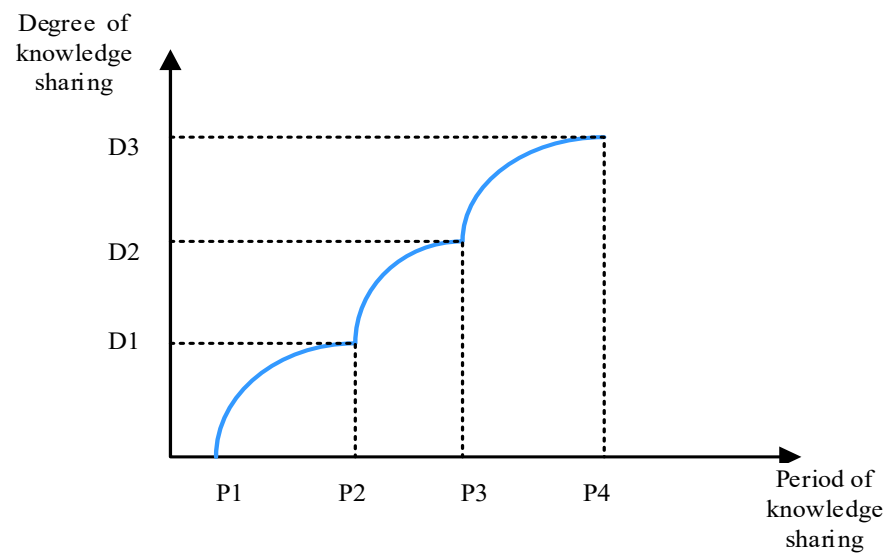


Fig. 7. Relationship of degree and period of knowledge sharing

\subsection{Knowledge sharing model}

The knowledge sharing model of music learning introduces the concept of knowledge field, and the knowledge learned by learners forms a knowledge field. At the first stage, music learners enter the knowledge field and collect knowledge, which is mainly shallow learning; the second is the organizational learning stage of knowledge, in which the learner makes a comparative analysis for their existing knowledge and learned knowledge for deep thinking and learning, and further discovers the inherent meaning of knowledge; at the third stage of communication, the learners continue to perform internalization and externalization through exchange learning from other scholars, and realize the transformation between socialization and personalization. In this process, the original knowledge is absorbed and the knowledge of itself is sublimated, achieving the knowledge updating and innovation. Innovative knowledge is further shared with others under the incentive effect, to deepen the knowledge in the original knowledge field, and update the knowledge in the knowledge field. The knowledge sharing process is shown in Figure 8.

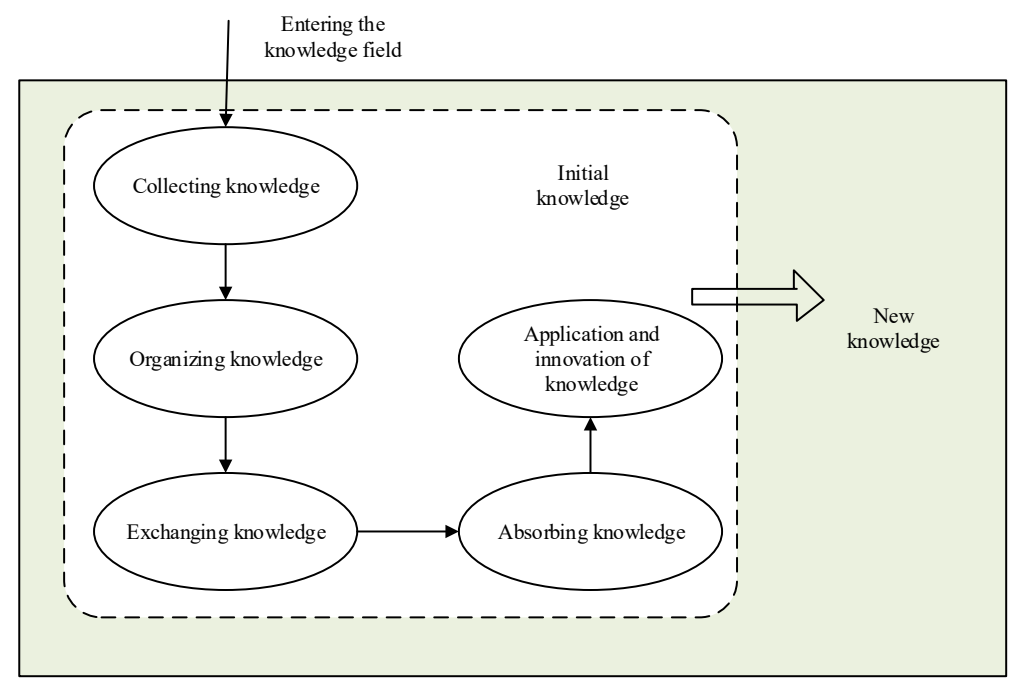

Fig. 8. The process of knowledge sharing and acceptance of new knowledge 


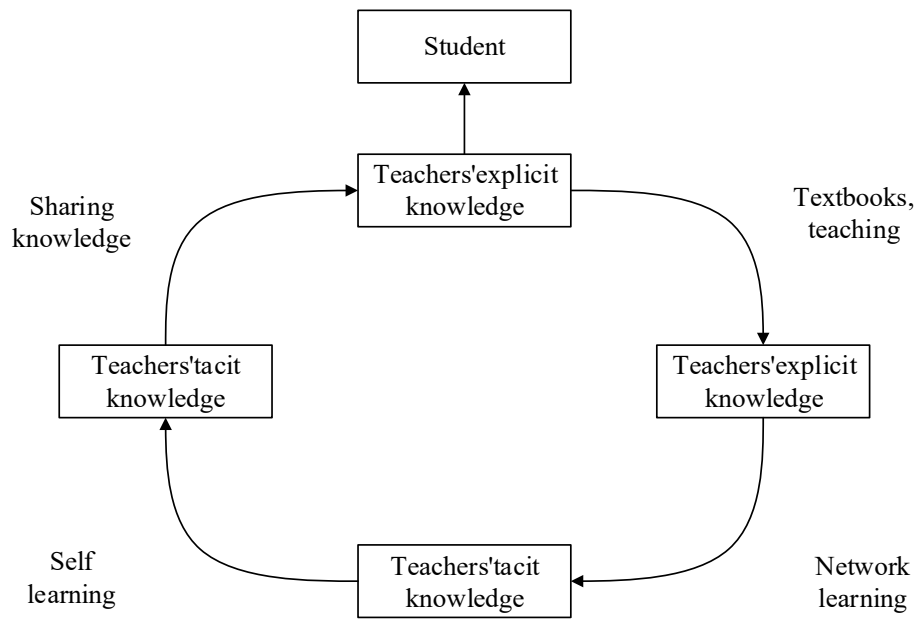

Fig. 9. Sharing model of music learning

The knowledge sharing model of music learning is designed according to the explicit and implicit nature of knowledge. Explicit knowledge is generally available through textbooks and teacher teaching. The implicit knowledge is generally shared in two ways: one is the use of network software or exchanges with professors, and the other is to refine and sublimate through their own learning. In the process of sharing, the explicit and implicit nature of knowledge is interchangeable, and the knowledge sharing is affected by external environment, knowledge level, organizational structure and incentive mechanism. The sharing model of music learning is shown in Figure 9.

\section{Establishment of a Music Learning Process Model}

\subsection{Music learning process model}

Under the new stimulus to the learners, the process of music learning starts with organizational learning, oriented towards problem-solving. The fundamental reason for organizational learning lies in the changes of internal and external environment. The process of music learning includes identification, searching, execution, updating, and promotion. The model is shown in Figure 10. The process of identification is to analyse the problems in music learning. Through this, the knowledge to solve the problem is obtained. Then, it needs to search for the knowledge in the knowledge base, find the knowledge that may solve the problem, and directly discover the organization needed. Afterwards, selective execution is performed. If the corresponding knowledge is not found, it needs to solve the problem through innovation. 


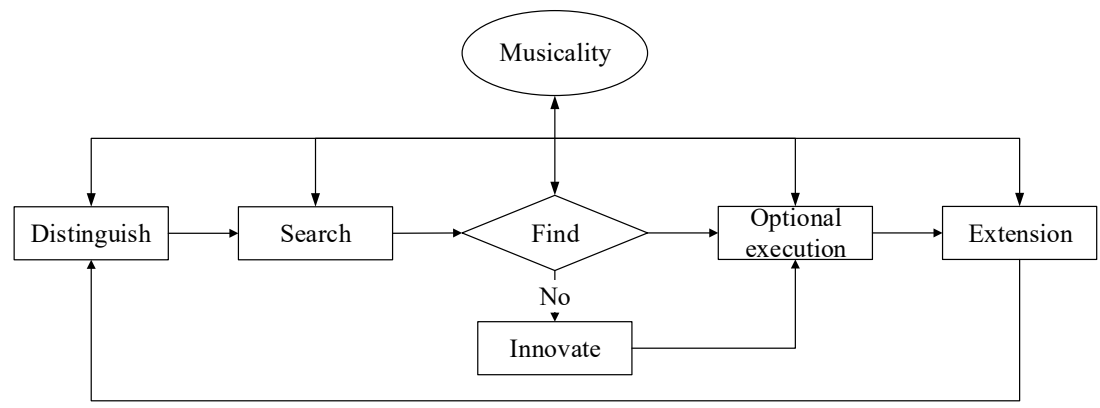

Fig. 10.Music learning process model

Innovation is a new method and strategy to solve problems. With the environment of music learning constantly changing, different problems also appear frequently, and the limited knowledge within the organization cannot fully solve the problem. Therefore, it is necessary to create new knowledge and deal with complex problems, and then update the knowledge of the organization to solve more problems. The execution is the process of implementing all the results. For the solutions already found, the execution step is essential. It is also the final link to solve the problem faced by the organization. The promotion of knowledge is to share and learn the problem solved through experience inherence so that the similar problem can be solved with the least cost.

The learning process of music is based on adapting to the environment. Learning is only a low-cost reproduction. The focus of music learning should be on the process of innovation and promotion, i.e., "double-ring learning." It can be seen from the music learning model that the whole process of learning forms a cycle; adding the step of innovation, it forms a double-loop learning process, which is more conducive to the sharing and promotion of music learning.

\subsection{Influence of knowledge sharing on music learning}

The influence of knowledge sharing on music learning mainly includes three aspects: the learning rate, the proportion of implicit and explicit knowledge, and music knowledge updating. Figure 11 shows the influence of knowledge sharing on learning rate. It can be seen from the figure that the rate of learning knowledge is basically a process of rapidly increasing and then slowly changing. Over time, different learning rates have a great influence on the level of music knowledge, and the level of music knowledge increases as the learning rate increases. 


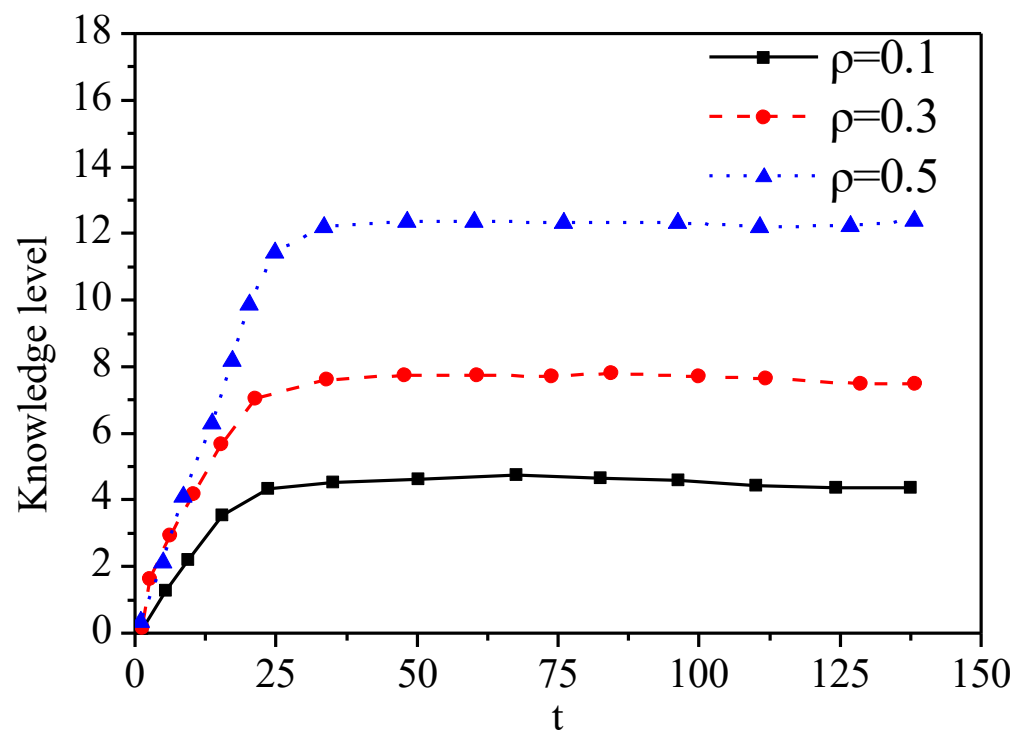

Fig. 11.The influence of learning rate on music knowledge level

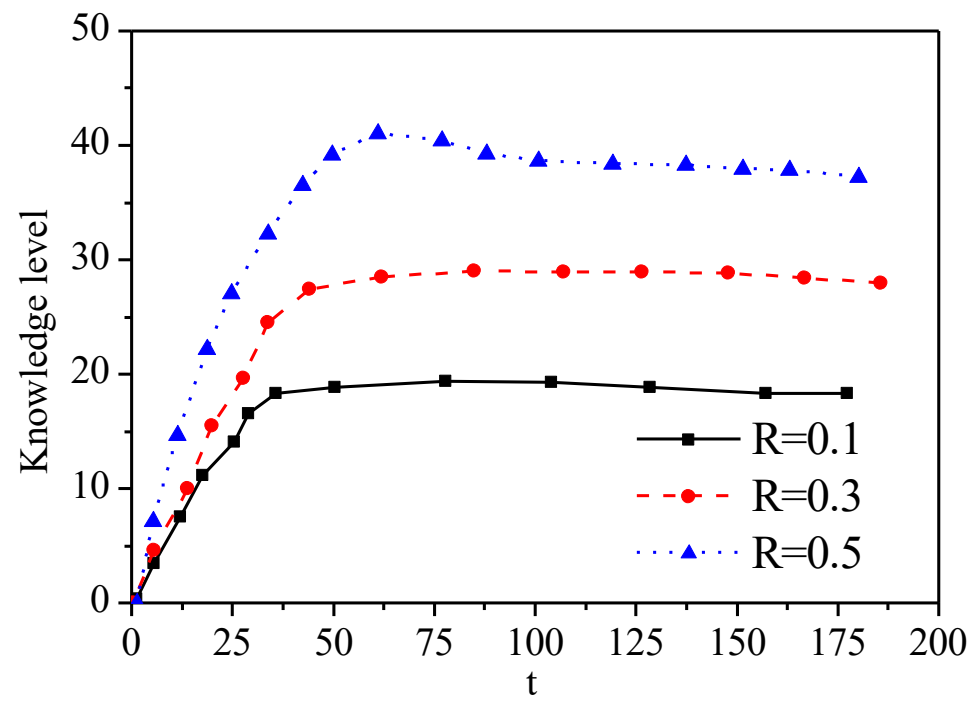

Fig. 12.The influence of explicit-implicit ratio on music knowledge level

Figure 12 shows the influence of music knowledge sharing on the proportion of explicit knowledge. It can be seen from the figure that as the proportion of explicit knowledge increases, the level of music knowledge gradually increases; when knowledge is completely close to dominant, the level of knowledge decreases instead, which indicates that at the high-dominance level, the organization contains most of 
the knowledge information of high performers; at the low-dominance level, the implicit knowledge level of the organization slows down the application of knowledge, finally improving the knowledge.

The updating time of music knowledge determines whether the knowledge in the knowledge base represents the latest knowledge, and also directly decides the level of organization, which has a very crucial impact. It can be seen from Figure 13, as the updating time of music knowledge increases, the music level of the organization gradually decreases, indicating that the updating time of the music knowledge is positively correlated with the knowledge representativeness of music organization and current knowledge level. Under the unpredictable environment of knowledge, the faster the update rate, the more adaptable it is to the changes in the environment.

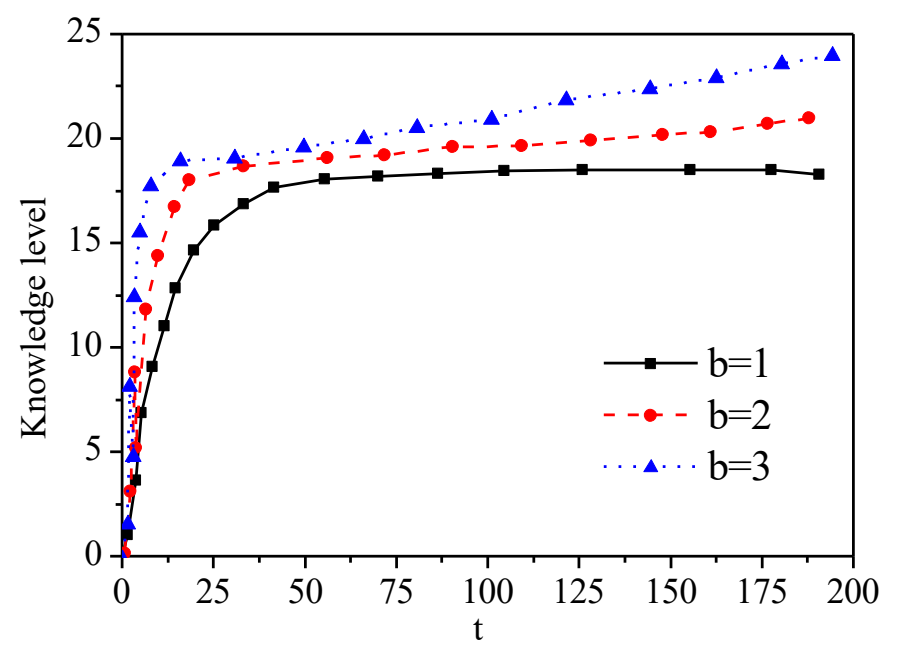

Fig. 13. The influence of updating time of music knowledge on organizational knowledge

\section{Conclusion}

This paper firstly analyses the structural characteristics and the transmission mode of knowledge. Then, in view of the relationship between knowledge sharing and knowledge innovation, it analyses the influencing factors in knowledge sharing, and proposes an improved music knowledge sharing model. Based on this model, the music learning process was systematically studied. The main conclusions are as follows:

- Knowledge sharing is highly self-incentive, and with higher degree of knowledge sharing, shared knowledge is more active and more likely to be shared again; drawing on the knowledge sharing related theory, the improved music knowledge sharing model was established 
- Integrating knowledge sharing with knowledge learning and innovation, a music learning process model was established, making the whole process of music learning form a cycle; after adding the step of innovation, it forms a double-loop learning process, which is more conducive to sharing and promotion of music learning

- Different learning rates have a great influence on the level of music knowledge, and the level of music knowledge increases with the improvement of learning rate under the fast-changing learning environment of music knowledge, the updating rate of knowledge increases, and the learning process model can be more adaptable to the changes in the environment

\section{Acknowledgement}

Name of higher education teaching project in Heilongjiang province: "Reform and promotion of Russian bel canto singing method in bel canto teaching in music colleges and universities" (Project No.: SJGY20170007) stage results

\section{References}

[1] Hew, K. F., Hara, N. (2007). Knowledge sharing in online environments: a qualitative case study. Journal of the American Society for Information Science and Technology, 58(14): 2310-2324. https://doi.org/10.1002/asi.20698

[2] Kuo, F. Y., Young, M. L. (2008). A study of the intention-action gap in knowledge sharing practices. Journal of the American Society for Information Science and Technology, 59(8): 1224-1237. https://doi.org/ 10.1002/asi.20816

[3] Hong, D., Suh, E., Koo, C. (2011). Developing strategies for overcoming barriers to knowledge sharing based on conversational knowledge management: a case study of a financial company. Expert Systems with Applications, 38(12): 14417-14427. https://doi.org/ 10.1016/j.eswa.2011.04.072

[4] Cyr, S., Choo, C. W. (2010). The individual and social dynamics of knowledge sharing: an exploratory study. Journal of Documentation, 66(6): 824-846. https://doi.org/10.1108/002 20411011087832

[5] Waring, J., Currie, G., Crompton, A., Bishop, S. (2013). An exploratory study of knowledge brokering in hospital settings: facilitating knowledge sharing and learning for patient safety. Social Science \& Medicine, 98: 79-86. https://doi.org/10.1016/j.socscimed. 2013.08.037

[6] Akhavan, P., Mahdi Hosseini, S. (2015). Social capital, knowledge sharing, and innovation capability: an empirical study of R\&D teams in Iran. Technology Analysis \& Strategic Management, 28(1): 1-18. https://doi.org/10.1080/09537325.2015.1072622

[7] Chiu, S. H. (2010). Students' knowledge sources and knowledge sharing in the design studio-an exploratory study. International Journal of Technology \& Design Education, 20(1): 27-42. https://doi.org/10.1007/s10798-008-9061-9

[8] MacCurtain, S., Flood, P. C., Ramamoorthy, N., West, M. A., Dawson, J. F. (2010). The top management team, reflexivity, knowledge sharing and new product performance: a study of the Irish software industry. Creativity \& Innovation Management, 19(3): 219-232. https://doi.org/10.1111/j.1467-8691.2010.00564.x

[9] Waring, J., Marshall, F., Bishop, S., Sahota, O., Walker, M., Currie, G., Fisher, R., Avery, T. (2014). An ethnographic study of knowledge sharing across the boundaries between 
care processes, services and organisations: the contributions to safe hospital discharge. Health Technology Assessment, 2(29): 1-160. https://doi.org/10.3310/hsdr02290

[10] Kaiser, S., Kansy, S., Seitz, G. M., Ringlstetter, M. (2010). The motivation of bloggers for organisational knowledge sharing and creation: a comparative case study to identify contingency factors influencing motivation. International Journal of Knowledge Management Studies, 4(1): 1-80. https://doi.org/10.1504/ijkms.2010.029788

[11] Boughzala, I., Briggs, R. O. (2012). A value frequency model of knowledge sharing: an exploratory study on knowledge sharability in cross-organizational collaboration. Electronic Markets, 22(1): 9-19. https://doi.org/10.1007/s12525-011-0080-0

[12] Shi, J. G., Lin, L. N. (2014). Empirical study on the incentive model of knowledge sharing within project-oriented organization based on knowledge potential theory. Journal of Applied Sciences, 14(3): 201-211. https://doi.org/10.3923/jas.2014.201.211

[13] Akhavan, P., Khosravian, F. (2016). Case study of a structural model to explore the effects of knowledge sharing on intellectual capital. Vine Journal of Information \& Knowledge Management Systems, 46(3): 338-352. https://doi.org/10.1108/vjikms-07-2015-0040

[14] Lindsay, E., Hawkins, J. (2003). Care study: the leg club model and the sharing of knowledge. British Journal of Nursing, 12(13): 784-790. https://doi.org/10.12968/bjon.20 03.12.13.11346

[15] Huang, C. C. (2009). Knowledge sharing and group cohesiveness on performance: an empirical study of technology R\&D teams in Taiwan. Technovation, 29(11): 786-797. https://doi.org/10.1016/j.technovation.2009.04.003

[16] Ghobadi, S., D"Ambra, J. (2012). Knowledge sharing in cross-functional teams: a coopetitive model. Journal of Knowledge Management, 16(2): 285-301. https://doi.org/10.1108/ 13673271211218889

[17] Pedrycz, W., Song, M. (2012). Granular fuzzy models: a study in knowledge management in fuzzy modeling. International Journal of Approximate Reasoning, 53(7): 1061--1079. https://doi.org/10.1016/j.ijar.2012.05.002

[18] Lin, C., Chang, S. (2008). A relational model of medical knowledge sharing and medical decision-making quality. International Journal of Technology Management, 43(4): 320. https://doi.org/10.1504/ijtm.2008.020554

[19] Ohkubo, S., Harlan, S. V., Ahmed, N., Salem, R. M. (2015). Conceptualizing a new knowledge management logic model for global health: a case-study approach. Journal of Information and Knowledge Management, 14(02): 1550015. https://doi.org/10.1142/s0219 $64921550015 \mathrm{x}$

[20] Shahpasand, S., Rahimzadeh, O. (2018). Investigating the role of internet of things in knowledge, management systems (case study: offering a resource, description model based on ontological study of smart store management (smart shopping cart). International Journal of Engineering and Technology, 7(3.5): 13. https://doi.org/10.14419/ijet.v7i3.5.15199

\section{$7 \quad$ Author}

Yifeng Li graduated from music college of China with a master's degree. He works in the school of art of northeast agricultural university and is engaged in opera singing and teaching. He has published many core papers. His research interests include electronic digital music, multimedia music technology and music education and teaching management.

Article submitted 2019-08-07. Resubmitted 2019-10-24. Final acceptance 2019-11-09. Final version published as submitted by the authors. 